\title{
Reforço escolar: espaço de superação ou manutenção das dificuldades escolares?
}

\author{
Marli Lúcia Tonatto Zibetti \\ Flávia Pansini \\ Flora Lima Farias de Souza
}

\section{Resumo}

O trabalho apresenta resultados de pesquisa desenvolvida em Rolim de Moura - RO, na qual foram investigados os procedimentos adotados pelas escolas quando as crianças enfrentam dificuldades na alfabetização. A pesquisa, de natureza qualitativa, foi desenvolvida em oito escolas públicas estaduais da área urbana e utilizou entrevistas, análise documental e observações participantes. Neste texto serão apresentados os dados relativos ao reforço escolar os quais indicam que, embora essa atividade esteja prevista nos projetos pedagógicos das escolas e os professores disponham de tempo específico na jornada de trabalho destinado a essa tarefa, as condições nas quais as crianças são atendidas, na maior parte das escolas analisadas, não favorecem o processo de aprendizagem. Os dados indicam, ainda, que em apenas uma das escolas participantes da pesquisa o coletivo de professores inseriu inovações interessantes na forma como o reforço foi desenvolvido, beneficiando as crianças em processo de alfabetização.

Palavras-chave: Aprendizagem, alfabetização, ensino fundamental.

\section{Tutoring: space for overcoming or keeping learning difficulties?}

\begin{abstract}
In this paper we present the results of a research developed in Rolim de Moura RO, Northern Brazil. We investigate the procedures adopted by the schools when the children face literacy difficulties. The qualitative research was developed in eight elementary public schools in the urban area. We conducted interviews, document analysis and participant observation. We present the data concerning the tutoring and we argue that they reveal that although this activity is prescribed in the educational projects prepared by the schools and teachers and that there is a specific time for the task within their working hours, the conditions in which children are attended, in most of the schools, do not favour the learning process. The data also indicates that in only one of the schools of our research, the group of teachers innovated the way of developing tutoring, thus benefiting children's literacy process.
\end{abstract}

Keywords: Learning, literacy, elementary education.

\section{Refuerzo escolar: ¿espacio de superación o mantenimiento de dificultades escolares?}

\section{Resumen}

El trabajo presenta resultados de investigación desarrollada en Rolim de Moura (Rondonia) en la que se indagó sobre los procedimientos de las escuelas frente a niños que enfrentan dificultades en la alfabetización. La investigación se desarrolló en ocho escuelas públicas estatales de área urbana y utilizó entrevistas, análisis documental e observaciones participantes. El texto presentará los datos relativos al refuerzo escolar que indican que, no obstante, esta actividad esté prevista en los proyectos pedagógicos de las escuelas y los maestros dispongan de tiempo específico en la jornada de trabajo destinado a esta tarea, las condiciones en las que los niños son atendidos en la mayor parte de las escuelas analizadas no favorecen al proceso de aprendizaje. Los datos señalan que solamente en una de las escuelas participantes de la investigación el colectivo de maestros introdujo elementos innovadores e interesantes al realizar el refuerzo promoviendo beneficios para los niños en proceso de alfabetización.

Palabras clave: Aprendizaje, alfabetización, enseñanza de primer grado. 


\section{Introdução}

O presente texto tem por objetivo discutir as ações de reforço escolar desenvolvidas com crianças que enfrentam alguma dificuldade na aprendizagem da leitura e da escrita em escolas públicas de um município no interior do Estado de Rondônia.

A adoção de políticas públicas específicas para atender a essa clientela, tais como a implantação do Ciclo Básico de Aprendizagem (CBA) e a garantia de tempo na jornada de trabalho dos professores da rede estadual para planejamento e atendimento aos alunos, faz dessa realidade um espaço propício para a realização de investigações que apontem os avanços e as dificuldades enfrentadas pelas escolas para atingir o objetivo de alfabetizar todas as crianças.

Num primeiro momento, pretendemos enfocar, neste trabalho, uma breve discussão sobre a questão do fracasso escolar na alfabetização, revisando estudos marcantes sobre a temática. Em seguida, apresentamos o método utilizado para a produção dos dados que ilustrarão, posteriormente, a discussão dos resultados obtidos. Para melhor compreensão das relações abordadas no presente estudo, os dados foram discutidos à luz de uma perspectiva crítica de educação e aprendizagem escolar.

\section{Fracasso escolar e alfabetização}

Quando uma criança ingressa no ensino fundamental, as expectativas familiares, escolares e das próprias crianças voltam-se para uma rápida aprendizagem da leitura e da escrita. Quando as expectativas não se confirmam e, por algum motivo, a criança não consegue aprender a ler e a escrever no tempo estabelecido pela escola (normalmente os dois primeiros anos de escolarização no ensino fundamental), tem início a produção de explicações que historicamente foram buscadas nos próprios indivíduos.

O trabalho de Proença (2002) sobre os encaminhamentos de crianças para atendimento psicológico indica que um grande número dos casos diz respeito às crianças que estão em processo de alfabetização. No estudo desenvolvido por Scortegagna e Levandowski (2004), as autoras constataram que houve predominância, dentre os encaminhamentos, de crianças cursando a segunda série do ensino fundamental (atual $3^{\circ}$ ano), ou seja, ainda em processo de alfabetização, decaindo o número destas conforme avançam as séries.

O fracasso na alfabetização inspirou estudiosos e especialistas a construírem diferentes explicações que foram mudando ao longo dos anos. A falta de "prontidão" da criança para o processo de alfabetização levou a escola a adotar diferentes atitudes em relação aos estudantes oriundos de classes populares, normalmente diagnosticados como "imaturos". Em alguns casos, meninos e meninas eram retidos na educação infantil, ou permaneciam em classes de alfabetização até que fossem considerados aptos a serem alfabetizados. Em outras situações, eram submetidos a uma série de exercícios de preparação, que eram centrados no desenvolvimento de habilidades perceptivo-motoras até que fossem considerados "prontos" a iniciar seu aprendizado do código alfabético. Essa maturidade deveria ocorrer por volta dos sete anos, idade considerada como ideal para se dar início à alfabetização, quando o cérebro da criança teria desenvolvido habilidades suficientes para absorver uma carga maior de informações.

Quando algumas crianças não apresentavam o desempenho esperado pela escola, no ritmo estabelecido com base em um padrão de normalidade considerado ideal, estas eram tidas como "anormais", portadoras de algum transtorno. Assim, as explicações dominantes sobre o fracasso escolar entre crianças em fase de alfabetização, durante muito tempo, voltaram-se para as chamadas disfunções psiconeurológicas da aprendizagem da leitura e da escrita. Segundo Proença (2002), quando se analisa de forma mais detalhada as descrições das dificuldades apresentadas pelas crianças para aprender a ler e a escrever, percebe-se que uma parcela dos professores e professoras realizam seu trabalho a partir de concepções de que os/as estudantes que desenvolvem um percurso diferente daquele esperado estariam comprometidas patologicamente e, por isso, careceriam de atendimento psicológico.

Pesquisas embasadas na perspectiva da deficiência cultural atribuíam o fracasso na alfabetização às condições de vida, deficiências culturais e linguísticas das crianças. Segundo Soares (1987, p. 20), o mito do déficit linguístico e cultural das crianças pobres baseia-se na suposição de que "as crianças das camadas populares chegam à escola com uma linguagem deficiente, que as impede de obter sucesso nas atividades e aprendizagem".

Na década de 1980, as ideias de Emília Ferreiro e Ana Teberosky (1999) sobre a Psicogênese da Língua Escrita transformaram de maneira revolucionária as concepções sobre alfabetização no Brasil. As bases conceituais do construtivismo passaram a nortear as políticas de alfabetização e também os programas de formação de professores. Segundo Sawaya (2000), esses estudos, ao contribuírem para mudanças nas concepções sobre a aprendizagem da leitura e da escrita, levaram a novos entendimentos sobre as dificuldades escolares das crianças de classes populares, fundamentando propostas de organização das escolas, como foi o caso do Ciclo Básico em várias redes brasileiras e da Progressão Continuada no Estado de São Paulo. Para a autora, no bojo do projeto de ampliação do tempo para o processo de alfabetização dos alunos de classes populares, encontra-se a justificativa de que a escola não está adaptada às condições sociais e culturais das crianças pobres.

Segundo Sawaya (2000), essas concepções foram utilizadas para justificar a necessidade de mudanças nas práticas pedagógicas e, portanto, na formação dos/as professores/as, bem como na ampliação do tempo escolar para a alfabetização das crianças pobres. Fundamentada em autores/as que questionam o discurso predominante sobre as concepções escolares de apropriação da leitura e da escrita que consideram como únicas formas válidas aquelas cons- 
truídas pelos grupos autorizados - pedagogos, linguistas, gramáticos, estudiosos da linguagem etc. - Sawaya (2000, p. 70) afirma que

As relações de poder e violência simbólica, que constituem as formas de aquisição e transmissão da leitura e da escrita via escola - mas não só - que são parte de um projeto político pedagógico nas suas formas de dominação social, não são questionadas, o que leva novamente a imputar às populações pobres e suas precárias condições de vida a razão do fracasso escolar e da sua "marginalidade social". (Destaque da autora).

Assim, mantém-se no contexto da alfabetização o que tem sido historicamente construído na educação brasileira, a culpabilização dos próprios indivíduos (alunos e suas famílias) pelo fracasso escolar. A eles têm sido atribuídas deficiências, dificuldades tanto físicas, cognitivas ou psicológicas, como sociais ou culturais. A solução para esses problemas tem sido buscada também no encaminhamento para diagnósticos aos profissionais da saúde. Segundo Moysés (2001, p. 47), na maioria dos casos de encaminhamento, "a peregrinação por consultórios de médicos, psicólogos, fonoaudiólogos, coincide com o início da escolarização, geralmente traumática, com o processo de rotulação imposto precocemente. Um processo avalizado, cientificizado pelos profissionais de saúde" (destaques da autora).

$\mathrm{O}$ atendimento individual das crianças encaminhadas aos serviços de Psicologia, imitando o modelo clínico, alheio à dinâmica da sala de aula e aos projetos de ensino, tem contribuído para acentuar o caráter elitista da educação, deixando aos menos favorecidos a falsa sensação de impotência quanto aos problemas vividos na escola e levando-os a acreditar que seus filhos e filhas realmente são portadores/ as de problemas emocionais.

Segundo Souza (2008), as discussões sobre o fracasso escolar passaram a ocupar espaço no campo da Psicologia Escolar e Educacional no bojo das críticas construídas pelos próprios profissionais da área sobre a atuação da Psicologia no campo da educação. Essa crítica interna e a constatação das pesquisas de que os problemas de aprendizagem recaíam maciçamente sobre as crianças de classes populares contribuíram para que fossem questionadas as explicações que, durante décadas, atribuíram as causas do não aprender a questões psicológicas, biológicas ou socioculturais, evidenciando o caráter ideológico dessas explicações decorrentes de concepções preconceituosas sobre os pobres e a pobreza.

Ainda segundo Souza (2008, p. 4), a partir do momento que se intensificaram as pesquisas sobre o cotidiano escolar, ancoradas em uma perspectiva crítica de educação, os estudos sobre o fracasso escolar permitiram:

Demonstrar que existe um complexo universo de questões institucionais, políticas, individuais, estruturais e de funcionamento presentes na vida diária escolar que conduzem ao seu fracasso, mantendo os altos índices de exclusão, principalmente das crianças e adolescentes das camadas mais pobres de nossa sociedade.

Tomando-se o processo de escolarização como foco em vez de enfatizar os problemas de aprendizagem, desloca-se "o eixo da análise do indivíduo para a escola e o conjunto de relações institucionais, históricas, psicológicas, pedagógicas e políticas que se fazem presentes e constituem o dia a dia escolar" (Souza, 2008, p. 4). E é nessa perspectiva teórica que se insere a presente pesquisa a qual busca compreender, com base na análise das condições em que as crianças estão inseridas no processo de escolarização, por que as mudanças introduzidas nos sistemas não têm trazido os benefícios esperados ao processo de aprendizagem.

\section{Método}

A pesquisa cujos dados fundamentam este texto foi desenvolvida em um município de 50 mil habitantes no interior do estado de Rondônia. Das dez escolas públicas estaduais do município, oito participaram do estudo, que foi realizado com base em uma abordagem qualitativa, na vertente dos estudos do cotidiano escolar que tomam por base uma compreensão crítica da realidade investigada, considerando, conforme Ezpeleta e Rockwell (1986, p. 13), que, ao lado de uma história documentada, existe outra história e existência não documentada, por meio da qual a escola toma forma material, ganha vida. "A homogeneidade documentada decompõe-se em múltiplas realidades cotidianas. Nesta história não documentada, nesta dimensão cotidiana, os trabalhadores, os alunos e os pais se apropriam dos subsídios e das prescrições estatais e constroem a escola".

Quando se escreve a história não documentada, por meio dos estudos do cotidiano, percebe-se que a versão documentada é parcial e produz certo efeito ocultador do movimento real. Na versão positivista, por exemplo, via-se no interior da escola o pedagógico e fora dela o político. As visões reprodutivistas, apesar de inserirem a transmissão ideológica no jogo pedagógico, continuaram a excluir o político do interior da escola. Para Ezpeleta e Rockwell (1986), a realidade escolar exige que a dimensão política seja considerada como constitutiva dessa realidade. Assim, para melhor compreensão dos processos educacionais, é fundamental "analisar a existência cotidiana atual da escola como história acumulada e buscar, no presente, os elementos estatais e civis com os quais a escola se construiu" (1986, p.13). Para construir os dados que permitiram a análise dessa realidade, foram utilizados os seguintes instrumentos: análise documental, entrevistas e observações participantes com registros em caderno de campo.

A análise de documentos foi utilizada para obtenção de informações sobre a legislação pertinente à regulamentação do Ciclo Básico de aprendizagem, bem como os projetos pedagógicos que fundamentam o trabalho das escolas no que se refere à alfabetização. 
Quanto às entrevistas, foram utilizadas para conhecer a opinião dos sujeitos envolvidos no processo pedagógico. Ou seja, foram ouvidas coordenadoras pedagógicas, orientadoras educacionais e professoras que atuavam nas turmas de Ciclo. Enquanto as coordenadoras e as orientadoras foram ouvidas individualmente, as professoras das turmas do CBA participaram de entrevistas coletivas, na perspectiva defendida por Kramer (2003), realizadas nas próprias escolas em que atuavam.

A observação participante foi um instrumento fundamental no processo de coleta de dados. Foi utilizada para conhecer como eram encaminhadas as atividades de reforço escolar e em que condições se desenvolviam. Foram realizadas em torno de 66 horas de observação nas oito escolas em que se realizou a pesquisa. O protocolo de observação garantia sempre uma descrição do local onde ocorria a atividade, o número de crianças envolvidas e o tipo de trabalho em desenvolvimento.

A análise de dados consistiu em triangular as informações das diferentes fontes e, à luz do referencial teórico, analisar como as escolas desenvolvem o trabalho de atendimento às crianças em processo de alfabetização durante as atividades extra-aula, denominadas reforço escolar.

\section{Resultados}

A organização da escolarização nas duas séries iniciais do Ensino Fundamental em forma de Ciclo Básico de Aprendizagem (CBA) foi implantada na rede estadual de ensino em Rondônia no ano de 1998 tendo como objetivo diminuir os altos índices de repetência e evasão escolar. 0 CBA se caracterizou como uma reorganização administrativa, curricular e pedagógica visando assegurar aos alunos o acesso, a permanência e o sucesso escolar, respeitando seu ritmo de aprendizagem (Rondônia, 1999).

Com a implantação do Ensino Fundamental de nove anos, ao final de 2007, algumas escolas mantiveram a proposta de Ciclo em seus projetos pedagógicos. Assim, os três primeiros anos de escolarização no Ensino Fundamental de nove anos, em quatro das oito escolas pesquisadas, passaram a funcionar como um bloco único, não havendo retenção entre eles. Ao final do $3^{\circ}$ ano as crianças não alfabetizadas eram retidas. Nas quatro escolas restantes, que decidiram não manter os Ciclos, a progressão ocorria entre o $1^{\circ}$ e o $2^{\circ}$ anos, ocorrendo a retenção ao final do $2^{\circ}$ para as crianças não alfabetizadas.

Na caracterização curricular e metodológica de todos os projetos escolares, assegurava-se aos alunos que apresentassem dificuldades na aprendizagem o oferecimento de recuperação paralela, também denominada de Laboratório de Aprendizagem, ou comumente "reforço escolar". Essas atividades eram ministradas em horário oposto àquele em que as crianças frequentavam as aulas regulares, durante duas horas diárias, por três ou quatro dias, perfazendo um total de seis a oito horas semanais.
No momento em que o aluno apresentar defasagem de conteúdos, implicando um baixo rendimento escolar, ele passará a frequentar a recuperação paralela em horário contrário à aula e com duração de 02 (duas) horas diária, num período de 04 (quatro) dias semanais, onde serão oferecidas metodologias alternativas e diversificadas contribuindo para o seu melhor desempenho escolar. Deverá deixar de frequentar a recuperação no momento em que suas dificuldades forem sanadas, devendo retornar sempre que houver necessidade (Projeto Prosseguir - Escola C ${ }^{1}$, 2008, p. 24).

O reforço era ministrado pelas professoras das próprias turmas, uma vez que os contratos de trabalho são de 40 horas, das quais 20 são cumpridas em sala de aula e as demais distribuídas entre recuperação/reforço e reuniões de estudo, avaliação ou planejamento, conforme estabelecido pela Lei 250/20012.

Em todas as escolas pesquisadas, o reforço era oferecido aos alunos e alunas do $1^{\circ}$ ao $5^{\circ}$ ano do ensino fundamental. As escolas A e $\mathrm{Y}$ eram as que ofereciam espaços relativamente adequados, ou seja, possuíam salas de aula disponíveis, no horário inverso, em número suficiente para o atendimento de no máximo dois grupos de alunos em cada espaço.

As escolas B, C, E e X, por não disporem de salas de aula em número suficiente para acolher os diferentes grupos, utilizavam também a biblioteca, sala de vídeo, sala dos professores, e/ou espaços de circulação (como pátios e corredores) para oferecer reforço. Também foram improvisadas, por uma escola, salas em madeira que eram mal ventiladas e mal iluminadas, normalmente sujas - pois as janelas eram de treliça, permitindo a entrada de poeira - nas quais existiam apenas carteiras, cadeiras e um quadro de giz. Sem condições, portanto, de oferecer ambiente propício para a aprendizagem.

A escassez de espaço físico levava à improvisação e era comum encontrarmos professoras com grupos de quatro a seis crianças reunidas nos mais diversos lugares, ou então dividindo a mesma sala de aula com outras três ou quatro professoras ao mesmo tempo. A utilização de corredores, salas de planejamento, pátios e bibliotecas revelava-se inadequada para o desenvolvimento de um trabalho de qualidade, uma vez que a circulação de pessoas, o barulho, a conversa das professoras atrapalhavam a concentração das crianças, gerando situações pouco produtivas do ponto de vista pedagógico. Na escola F, em 2008, o reforço era desenvolvido no intervalo entre um turno e outro, no horário de

1 Na pesquisa, as escolas foram denominadas pelas letras $A, B, C$, $D, E, F, X$ e Y.

2 O parágrafo $4^{\circ}$ do Art. $13^{\circ}$ da Lei Complementar 250/2001 determina: "A jornada de quarenta horas semanais do professor do nível 1 e nível 3, com formação para as primeiras séries do ensino fundamental, em função docente em turmas de $1^{\mathrm{a}}$ a $4^{\mathrm{a}}$ séries e da educação infantil, inclui vinte horas de aulas e vinte horas de atividades, das quais doze horas serão destinadas a trabalhos coletivos na unidade escolar" (Rondônia, 2001, p.5). 
almoço, pois não havia espaço disponível em outro horário. Situação que ainda perdura.

As condições em que era desenvolvido esse momento do processo educativo evidenciavam que o reforço caracterizava-se como uma atividade executada pela escola por ser obrigatória para o cumprimento da carga horária contratual das professoras. Entretanto, se essa carga horária era obrigatória para as professoras, o mesmo não acontecia em relação aos alunos e alunas, pois sempre que a escola ou os próprios docentes precisavam dispor de tempo para outras demandas, o horário de reforço era suspenso. Ou seja, enquanto a ausência de um professor ou professora no horário normal de aulas implicava a reposição desse dia para que se pudesse garantir, formalmente, o cumprimento dos 200 dias letivos, o mesmo não ocorria em relação aos horários destinados às atividades de reforço.

Analisando os registros de observação, conseguimos detectar as seguintes razões pelas quais o reforço não foi realizado em alguma ou em várias escolas, durante um dia, ou durante semanas inteiras: a) Participação das professoras em atividades de formação continuada; b) Faltas das professoras; c) Conselho de Classe; d) Estudo de algum documento encaminhado para a escola ou elaboração de projetos; e) Realização de Feira de Conhecimento; f) Festas na escola ou comemorações de datas como Páscoa, Dia das mães e Dia das crianças; g) Participação da escola em atividades culturais da cidade como cavalgada de abertura da exposição agropecuária; h) Greve dos/as professores/as; i) Alunos chamados não compareceram.

Embora, no discurso das professoras, das equipes pedagógicas e conforme registrado em todos os projetos de CBA, o reforço escolar fosse considerado uma atividade importante para auxiliar as crianças que não estavam apresentando um desenvolvimento condizente com a turma, na prática, o que se percebia é que essa não era uma atividade priorizada pelo coletivo da escola ${ }^{3}$. Além disso, a administração escolar negligenciava a adoção de medidas para seu aperfeiçoamento, não havendo planejamento e acompanhamento pedagógico dessas atividades.

Outro aspecto que corrobora nossas afirmações é o fato de que, após anos de implantação de horário específico para atendimento aos alunos na jornada dos/as professores/ as, os espaços físicos necessários para sua efetiva realização ainda não tenham sido garantidos. Além disso, apesar das insistentes solicitações das professoras, não havia merenda para as crianças que frequentavam o reforço.

Do ponto de vista pedagógico, a pesquisa evidenciou que a ausência de um projeto próprio para esse tipo de atividade dificultava o acompanhamento por parte da equipe pedagógica e também parecia trazer poucos benefícios aos alunos e alunas, quando não contribuía para aprofundar o estigma sobre as crianças que precisavam de ajuda.

Apresentamos a seguir um trecho de observação realizada na Escola B que evidencia a forma como esse tipo de atividade era desenvolvido nas escolas observadas. Nesse

3 Exceto na Escola $Y$, cuja experiência será apresentada mais adiante. dia o reforço estava sendo realizado na sala de planejamento, local onde ficam guardados os materiais das docentes que atuam nas séries iniciais.

\section{Situação I: Escola B}

Chego à escola às 12h45min, dirijo-me à direção e esta pede para que eu espere a chegada da professora. É horário de entrada das turmas do período vespertino e observo que algumas crianças, que não estão uniformizadas, dirigem-se à sala de planejamento; supus então que ali deveria ser o reforço e fui ao encontro das mesmas. A sala onde acontece o reforço é a mesma onde ficam os materiais das professoras das séries iniciais: é uma sala pequena, onde há um quadro negro, armários e duas mesas: uma grande com oito cadeiras, três delas ocupadas com crianças da primeira série; a outra pequena, com quatro cadeiras na qual acontecia o reforço da professora Lúcia ${ }^{4}$ do terceiro ano do Ensino Fundamental.

Apresento-me e a professora pede para que eu escolha um lugar para sentar. Prefiro ficar na mesa maior que fica ao lado de onde a professora e o aluno estavam.

Assim que sentei, a professora me conta que é difícil trabalhar com Carlos, apesar de ser um aluno esforçado: "Com esse é difícil porque do jeito que leva as tarefas pra casa, volta".

Apesar de ainda não ser 13h, o reforço já havia começado e, por volta das 13h05min, chega Sílvia com seu capacete rosa e a mochila da mesma cor. A professora pede para que Carlos grife, no texto "Sapo Cururu" (impresso em uma folha), as palavras que ele encontra mais dificuldade em ler e em escrever. Enquanto isso, pede para Sílvia que tire o caderno de dentro da mochila. Com a minha presença, a aluna aparenta estar encabulada, e a professora Ihe explica que a observadora não vai fazer mal, que só veio olhar o que acontecia no reforço. Enquanto Sílvia vira para tirar o caderno de dentro da bolsa, entra uma aluna aparentando ter uns 13 anos e esta pede informações para a professora a respeito do seu irmão que é aluno da mesma turma: "Vixi, ele está muito desinteressado, avoado, tem que por para ler mais, se continuar assim vai ficar!".

Depois de grifar as palavras, Carlos entrega o texto para a professora, que avisa ao aluno que vai iniciar o ditado: "Já escreveu ditado aí em cima? Agora pule uma linha e escreva: Sapo, Cururu...".

Enquanto Carlos escreve, a professora pede para Sílvia grifar as palavras que ela tem dificuldade de ler e escrever em uma folha com o mesmo texto. Assim que Silvia Ihe entrega a folha com as dificuldades, a professora reinicia o ditado: "Sapo, Cururu, na beira do rio, quando..." [...]

Por volta das $13 \mathrm{~h} 17 \mathrm{~min}$, chega a professora das crianças que estavam na outra mesa: dois meninos e uma menina. Entram outras professoras que vêm pegar seus materiais para dar reforço em outra sala. A sala fica muito barulhenta e, antes de sair, uma professora vira para a professora Lúcia e reclama do cansaço. Lúcia fala que só aguenta estar ali porque no domingo dormiu o dia todo. A outra professora sai da sala e vai para a biblioteca onde vai realizar o reforço da sua turma. Ficam na sala somente as professoras Lúcia e a do $1^{\circ}$ ano com seus respectivos alunos.

Carlos entrega seu caderno à professora e esta pergunta: "Você tem

4 Foram utilizados nomes fictícios para denominar as pessoas envolvidas nas situações observadas. 
refletido sobre a lição em casa? Não! Tô cansada, viu? Já li junto, reforço... e você não melhora?".

Com meia hora de atraso, chega Bruno, e Lúcia questiona o porquê do atraso, já que o aluno mora "colado" na escola. Pede para que Bruno comece a ler o texto do Sapo Cururu e entrega a Carlos outro texto, "Escravos de Jó". Carlos demonstrou que já conhecia o texto e leu com facilidade. Enquanto isso, Sílvia terminava de escrever o texto do Sapo Cururu. Assim que terminou, entregou seu caderno à professora, que corrige, vira para a observadora e comenta que Sílvia só acertou duas palavras. Lúcia pede para que a aluna reescreva as palavras que errou. Quando começa a tarefa que Ihe foi atribuída, Sílvia aponta para o caderno e pergunta que palavra era aquela. A professora responde: "E eu quem sei? Você quem escreveu! Olha, Sílvia, eu trabalho isso desde o bimestre passado, trabalho esse mesmo texto e você ainda não aprendeu?".

Na outra mesa, na mesma sala, a turma da $1^{\text {a }}$ série montava palavras com letras móveis e figuras. Um dos alunos do grupo formava as palavras antes dos outros, depois ia ajudá-los e empolgava-se falando alto, o que chamava a atenção das crianças da professora Lúcia. [...]

Uma hora após o início do reforço, chega mais uma aluna do primeiro ano e todas as crianças comentam o atraso. As professoras as repreendem [...]. A coordenadora pedagógica entra na sala e pergunta por que Carlos se encontrava no reforço. A professora Lúcia explica que é para ele treinar a leitura. Sílvia mostra para a coordenadora a capa do seu caderno, que é ilustrado com um desenho animado bastante conhecido. E a coordenadora adverte: "Não adianta ter o caderno bonito se a letra for feia, por isso capriche, viu?" [...] (Observação, 28/08/2008 - Escola B).

A situação apresentada foi escolhida por nos permitir discutir questões que eram comuns a várias escolas observadas, evidenciando problemas semelhantes na oferta dessa atividade. Inicialmente, podemos destacar que o reforço tem início em momentos diferentes para cada profissional e também para as/os alunas/os. Eram comuns professoras esperando alunos/as ou estes procurando professoras que ainda não haviam chegado ou então se encontravam em outro local da escola. Além disso, a cena apresentada revela como a atividade sofre interrupções ao longo de um curto período de realização: a chegada de um aluno por vez, a chegada de outras professoras, a entrada na sala de alunos/ as de outras turmas, a interrupção da coordenadora. Sem deixar de considerar que a presença de dois grupos de alunos de turmas diferentes no mesmo espaço, utilizando materiais e realizando atividades distintas, também é motivo de distração.

Apesar de contar com a presença de três alunos naquele dia, a professora encaminhou a mesma atividade para que fosse feita individualmente. Cada um deles realizou-a em tempos diferentes, levando a professora a atendê-los de maneira individual. Também merece discussão o tipo de atividade proposta pela professora e as intervenções realizadas. Considerando-se que são crianças de $3^{\circ}$ ano, a utilização de textos conhecidos de memória apresenta poucos desafios no campo da leitura, aspecto que, segundo a professora, precisava ser melhorado. Por outro lado, o encaminhamento da atividade enfatizava a escrita, pois a professora orientou as crianças a prestarem atenção, antecipadamente, nas palavras que teriam alguma dificuldade em escrever, estimulando as crianças a utilizarem a memória para guardar as formas que teriam que reproduzir e deixando de refletir sobre as diferentes possibilidades que podem surgir na escrita de uma palavra.

Em relação à atividade encaminhada, também é possível generalizar o observado nessa cena para várias outras escolas. Embora as coordenadoras afirmassem que havia uma tentativa de trabalhar com atividades diferentes daquelas utilizadas no dia a dia da sala de aula, a maior parte das atividades observadas no momento do reforço era muito semelhante, senão as mesmas realizadas em sala de aula. Durante as observações, o que mais presenciamos foram atividades de leitura de textos, escrita com letras móveis, ditado e cópias.

A utilização de jogos foi presenciada em cinco ocasiões, entretanto, em apenas uma delas, o conteúdo trabalhado foi da área de linguagem. Nas demais situações em que presenciamos o uso de jogos, os conteúdos eram da área de matemática, tais como adição, multiplicação, dezenas ou formas geométricas (blocos lógicos) e, em um dos casos, a professora utilizou quebra-cabeças. Durante o período observado, 90\% das atividades desenvolvidas estavam relacionadas a conteúdos de Língua Portuguesa e 10\%, a conteúdos de Matemática. As demais disciplinas não estiveram presentes no reforço durante o período observado.

Na Situação 1, também fica evidente a forma pouco encorajadora por meio da qual a professora dirigia-se às crianças. Esse tipo de atitude, mais comum do que gostaríamos, pode estar contribuindo para que muitas crianças sintam-se desestimuladas e evitem comparecer ao reforço, uma vez que, de acordo com as coordenadoras e as professoras, a principal dificuldade enfrentada em relação ao reforço é o não comparecimento dos alunos. Constatação esta que levou a escola $\mathrm{Y}$ a implementar uma forma diferenciada de encaminhamento das atividades de reforço, conforme apresentado no item a seguir.

\section{Construindo uma prática coletiva de reforço escolar}

A Escola $Y$ percebeu a necessidade de alterar a forma como vinha ocorrendo o reforço a partir da constatação de que havia uma grande diversidade de níveis de conhecimento nas turmas, decorrente tanto da alta rotatividade de alunos/as quanto da adoção do Ciclo, que permite o avanço dos alunos, mesmo sem estarem alfabetizados. Além disso, as crianças atendidas no reforço apresentavam pouco avanço na aprendizagem da leitura e da escrita e tinham uma baixa frequência nessas atividades.

De acordo com a Coordenadora Pedagógica da Escola Y, do ponto de vista pedagógico

Havia uma prática individualizada de cada professora atender apenas seu grupo de alunos. Isso levava à repetição de atividades já oferecidas em sala, não havia trocas entre 
as professoras e tínhamos dificuldades na distribuição dos grupos no espaço físico que era insuficiente. (Entrevista Coord. Pedagógica Escola Y, 2009).

A escola então passou a organizar o que denominou grupos de apoio pedagógico. Ou seja, a partir da avaliação do desempenho dos/as alunos/as de cada série, estes eram organizados em grupos que eram atendidos por uma ou mais profissionais durante o reforço, independentemente da turma a que pertenciam. Assim, as crianças foram agrupadas para o reforço em Grupo de alfabetização I, formado por alunos/ as em processo de compreensão do sistema alfabético da escrita, e Grupo de Alfabetização II, formado por alunos/as alfabéticos em processo de aperfeiçoamento da leitura e da produção escrita. Em alguns casos, agrupavam-se alunos/ as de séries diferentes, observando a similaridade dos níveis de conhecimento e as necessidades de aprendizagem de cada aluno/a.

Para a organização dos grupos, as professoras e a Coordenadora Pedagógica utilizavam um diagnóstico inicial e periódico da aprendizagem dos/as alunos/as que era discutido em encontros entre as profissionais para análise das produções das crianças, definição ou reorganização dos grupos de estudantes e planejamento das atividades a serem desenvolvidas.

Além das mudanças na composição dos grupos e também no fato de que um mesmo grupo de alunos/as era atendido em atividades coletivas que eram coordenadas por uma professora, mas auxiliadas por várias outras, houve também alteração no tipo de atividades propostas.

Para as crianças que ainda não haviam construído a base alfabética investimos em atividades lúdicas, tais como: boliche (com letras e números), jogo stop, jogo de memória, loto-leitura, forca, bingos, atividades com letras móveis, pois elas estavam na escola em outro horário, após já terem frequentado as aulas regulares. Para as crianças que já haviam construído a base alfabética, mas necessitavam aperfeiçoar o domínio de aspectos específicos da leitura e da escrita, procuramos oferecer atividades que ajudassem nisso. Então procuramos realizar análise de textos focando em aspectos linguísticos e estilísticos; leitura e produção de textos de diferentes gêneros textuais; revisão coletiva de textos; sequências didáticas enfocando aspectos problemáticos na escrita das crianças, tais como a segmentação. E fizemos muitas rodas de leitura. (Entrevista Coord. Pedagógica Escola Y, 2009).

Do ponto de vistas das professoras e da Coordenação Pedagógica da Escola $Y$, a implantação dessa nova forma de atendimento às crianças no horário de reforço trouxe uma série de aspectos positivos, que podem ser assim resumidos: a) Melhor aproveitamento dos espaços e tempo disponível para a tarefa; b) As aulas tornaram-se mais dinâmicas e prazerosas para alunos/as e professoras; c) Maior motivação dos/as alunos/as e consequentemente a diminuição significativa das faltas das crianças ao reforço; d) Avanço significativo na aprendizagem dos alunos.

A escola constatou que era bastante positivo para as professoras contar com o "olhar das colegas" sobre as dificuldades enfrentadas pelas crianças, o que intensificou as trocas de experiências, fortalecendo a proposta de alfabetização adotada pela escola, funcionando como um processo de formação continuada da equipe. Esse contexto levou a um maior comprometimento da Coordenação Pedagógica com o acompanhamento do trabalho e da aprendizagem nos grupos de apoio pedagógico e também ampliou a compreensão por parte da equipe gestora da organização do trabalho na alfabetização.

Todavia, algumas dificuldades para a implementação da proposta foram sentidas pelo grupo. "A principal dificuldade foi o envolvimento de alguns colegas com o trabalho coletivo. Isso foi uma das maiores barreiras para o nosso trabalho" (Entrevista Coord. Pedagógica Escola Y, 2009). Ou seja, é preciso investimento na construção de um coletivo escolar que depende inclusive da estabilidade da equipe na mesma escola. Conforme Peron (2001, p. 355), "as esferas de decisão encontradas nos espaços escolares estão organizadas a partir de formas individualizadas de organização do trabalho, em detrimento de procedimentos coletivos envolvendo os membros da instituição", o que representa um dos grandes fatores determinantes do fracasso escolar, principalmente no contexto da alfabetização.

Outro aspecto a ser enfrentado é a administração do tempo do grupo de maneira a permitir o planejamento conjunto das atividades necessárias ao horário de reforço. Aspecto bastante difícil, de acordo com as profissionais, devido à cultura da individualidade presente nas escolas, mas também em relação à ausência de espaços físicos favoráveis ao estudo e à reflexão no ambiente escolar.

Além dos aspectos apontados, a proposta implementada enfrentou dificuldades em relação à insuficiência de materiais necessários à produção de atividades, pois a escola contava com apenas um computador e uma impressora para atender a todas as professoras e havia falta de materiais como papel, tinta, cartolina e outros.

\section{Discussão}

O contexto em que se desenvolve o processo de alfabetização nas escolas investigadas tem passado por várias alterações a partir da implantação de diferentes políticas públicas, dentre as quais podemos destacar: a ampliação do tempo para a alfabetização, garantida pela organização das séries iniciais em ciclo; a entrada das crianças aos seis anos no ensino fundamental; a formação do quadro docente em nível superior e, em grande número, em pós-graduação; a garantia de tempo, dentro da jornada de trabalho, destinado ao planejamento e atendimento aos alunos. Essas medidas têm sido apontadas, tanto por pesquisadores, quanto pelos próprios docentes, como condições básicas para elevação da qualidade do ensino. Porém, isso pouco tem ocorrido 
na realidade investigada, de acordo com o que revelam os números do rendimento escolar e de contínuos encaminhamentos a médicos e psicólogos de crianças em processo de alfabetização, conforme apontamos em outros trabalhos (Zibetti, Souza, \& Queiroz, 2010).

As condições inadequadas para a realização de atividades que deveriam auxiliar as crianças cujas necessidades de aprendizagem não foram atendidas durante as aulas regulares, além da forma como essas atividades estão sendo desenvolvidas, incidem diretamente sobre o não comparecimento das crianças e também nos resultados obtidos. As atitudes das professoras que tecem comentários depreciativos sobre os alunos/as diante dos mesmos, ou dirigem-se a eles/ as de forma desestimulante, desconsiderando as causas do erro, caracterizam-se como formas extremamente perversas de reforçar a exclusão, sob o disfarce de contribuir para a superação do fracasso.

O contexto criado no atendimento às crianças convocadas para participar de atividades de reforço pode caracterizar-se como um agravante a mais para o fracasso escolar se a forma como são atendidas reforçar os estereótipos e as críticas das professoras sobre seu desempenho. Por outro lado, atividades centradas no trabalho coletivo, focadas nas reais necessidades dos alunos podem ser bastante úteis ao avanço no processo de aprendizagem.

Quando as atividades são desenvolvidas por uma professora exclusivamente para seu pequeno grupo de alunos/as, o acompanhamento ocorre de forma individualizada. Em algumas situações, esse atendimento mais próximo pode caracterizar-se como favorecedor do conhecimento da professora sobre os alunos e alunas e uma intervenção que aproxima educadora e educandos. Em outras situações, essa proximidade pode gerar situações de extrema cobrança, que deixa as crianças "apavoradas" diante das tarefas. Por outro lado, ao reunir, em pequenos grupos, alunos com dificuldades semelhantes, mas de professoras diferentes, pode-se obter benefícios para ambos. Os alunos vão contar com uma forma diferente de atendimento, e as professoras podem trocar opinião sobre o desempenho das crianças, compreendendo melhor suas dificuldades e necessidades.

Embora as observações não tenham conseguido abranger todo o conjunto de professores/as que atuam nas oito escolas pesquisadas, os elementos aqui apresentados nos permitem questionar, do ponto de vista institucional, a validade de uma medida implantada como apoio às crianças supostamente com dificuldades de aprendizagem. Espaços físicos inadequados, falta de preparo, tanto do corpo técnico, quanto pedagógico, equívocos na compreensão das necessidades de aprendizagem das crianças parecem ser aspectos que têm contribuído para que o fracasso no processo de alfabetização se mantenha na maior parte das escolas.

A experiência da Escola $Y$ indica que há questões que podem ser enfrentadas no âmbito da escola, entretanto, há outras que dependem da atuação do poder público, como a garantia de espaços e materiais suficientes para o bom andamento do trabalho pedagógico.
Conforme aponta Patto (2005, p. 30), "Quem conhece por dentro o cotidiano da maioria das escolas públicas, sobretudo das que se situam nas regiões mais empobrecidas e desatendidas da cidade, sabe que sob a aparência de melhora esconde-se uma realidade que agride e frustra diariamente os participantes da vida escolar".

A forma como essas medidas legais são implantadas pelos sistemas, excluindo-se os profissionais das escolas e também o público atendido das discussões, proposições ou medidas a serem adotadas para viabilização das propostas, reflete a gestão autoritária do sistema pelos órgãos centrais, que, por sua vez, é reproduzida no nível das instituições. Há os que definem as políticas, os que recebem as ordens e as repassam àqueles a quem compete executá-las, muitas vezes improvisando as condições que não são dadas pelo poder público. Essa divisão do trabalho escolar entre os que planejam e os que executam reproduz uma dicotomia que contribui para a consequente exclusão dos menos favorecidos. Na situação em análise, evidencia-se esse descompasso. Se, por um lado, garante-se o tempo na jornada de trabalho para que professores e professoras atendam aos alunos, por outro lado, esse tempo não se faz acompanhar de medidas que permitam seu aproveitamento, tais como espaços físicos e materiais didáticos apropriados, bem como apoio pedagógico especializado.

Outra característica dessas alterações é a fragmentação e a desarticulação entre elas. Isso ocorre tanto em relação às propostas de reorganização do sistema, quanto à formação de professores. Ou seja, a formação em nível superior, ou em nível de especialização dos docentes em exercício, ou mesmo daqueles sem experiência na docência, tem sido desenvolvida em total distanciamento das escolas públicas nas quais irão atuar, ou dos projetos governamentais em curso em tais instituições. Além disso, o espaço profissional não é considerado formativo e espera-se que o professor ou professora, ao chegar à escola, seja capaz de imediatamente apresentar-se como profissional pronto e competentemente preparado.

O trabalho docente é uma prática social que se faz no cotidiano dos sujeitos nela envolvidos e nessa prática social é que esses sujeitos se constituem como seres humanos, ao se apropriarem da experiência sócio-histórica da humanidade que se acumula de forma objetiva no mundo. Toda a produção humana é expressão da história da natureza humana. O próprio processo de apropriação das produções humanas é, ao mesmo tempo, o processo de formação das faculdades específicas de homens e mulheres. Sobre essa questão, Leontiev (1978, p. 268) assevera:

Devemos sublinhar que este processo é sempre ativo do ponto de vista do homem. Para se apropriar dos objetos ou dos fenômenos que são o produto do desenvolvimento histórico, é necessário desenvolver em relação a eles uma atividade que reproduza, pela sua forma, os traços essenciais da atividade encarnada, acumulada no objeto. 
É, portanto, no exercício da docência que o professor objetiva-se, constrói-se e participa da construção do processo educacional no interior da sociedade na qual está inserido, uma vez que o psiquismo humano se estrutura a partir da atividade humana, ou seja, das apropriações que os indivíduos fazem a partir dos elementos materiais e simbólicos da cultura humana. "A estrutura da consciência humana está regularmente ligada à estrutura da atividade humana" (Leontiev, 1978, p. 99). Dessa forma, a prática pedagógica é, ao mesmo tempo, a expressão do saber docente e fonte de desenvolvimento desse saber, pois das necessidades práticas que decorrem da atuação cotidiana em sala de aula originam-se as buscas teóricas dos/as professores/as que, a partir das apropriações feitas em função das demandas do real, desencadeiam a produção de novos saberes.

Por isso é tão importante que o espaço escolar seja constituído como um espaço de elaboração, experimentação e consolidação de novas formas de atuação, gestadas, implementadas e avaliadas coletivamente como garantia de produção de novos saberes e aperfeiçoamento contínuo das práticas pedagógicas a serviço dos aprendizes. Porém, essa articulação coletiva dificilmente ocorre no espaço escolar. A fragmentação do trabalho docente no interior da escola, a inexistência de projeto pedagógico coletivo, a ausência de metas claras para a progressão das aprendizagens têm gerado práticas altamente excludentes, tanto em relação aos alunos, quanto às próprias docentes.

Entretanto, as escolas são locais de contrastes e, embora na maior parte delas as ações de reforço escolar tenham sido desenvolvidas de forma rotineira e mecânica, em outra a apropriação do horário de planejamento e reforço e a sua transformação em instrumentos a serviço das necessidades das crianças e das próprias docentes têm feito surgir formas novas de atuação que passam a inserir os sujeitos em contextos formativos mais contributivos para a aprendizagem. Isso evidencia que apenas por meio de uma organização coletiva dos educadores é que será possível superar práticas inadequadas, como as discutidas neste texto.

Esses contrastes apontam para a existência de possibilidades de atuação em favor dos alunos, mesmo em um contexto histórico de "descaso secular pela instrução pública" (Patto, 2005, p. 52) no Brasil. E o alargamento dessas possibilidades de atuação demanda intervenções, tanto no campo político mais amplo, quanto no espaço micro da escola e da sala de aula.

\section{Referências}

Ezpeleta, J., \& Rockwell, E. (1986). A escola: relato de um processo inacabado de construção. Em J. Ezpeleta \& E. Rockwell, Pesquisa participante (pp. 9-30). São Paulo: Cortez: Autores Associados.

Ferreiro, E., \& Teberosky, A. (1999). Psicogênese da Língua Escrita. Porto Alegre: Artmed.

Instrução Normativa 001. (1999, 05 de julho). Fixa normas para operacionalização do Projeto Caminhar nas Unidades Escolares da rede pública estadual de ensino. Governo do Estado de Rondônia. Porto Velho. Secretaria de Estado da Educação.

Kramer, S. (2003). Entrevistas coletivas: uma alternativa para lidar com diversidade, hierarquia e poder na pesquisa em ciências humanas. Em S. J. Souza \& S. Kramer (Org.), Ciências humanas e pesquisa (pp. 57-76). São Paulo: Cortez.

Lei 250 de 21 de dezembro de 2001. (2001). Institui o plano de Carreira, Cargos e Remuneração para os integrantes do Quadro do Magistério do Estado de Rondônia. Governo do estado de Rondônia.

Leontiev, A. (1978). O desenvolvimento do psiquismo. Lisboa: Livros Horizonte.

Moysés, M. A. A. (2001). A institucionalização invisível: Crianças que não-aprendem-na-escola. Campinas, SP: Mercado das Letras; São Paulo: FAPESP.

Patto, M. H. S. (2005). Exercícios de indignação: escritos de educação e Psicologia. São Paulo: Casa do Psicólogo.

Peron, S. C. (2001). As condições institucionais para a organização do trabalho pedagógico. Em S. Leite (Org.), Alfabetização e letramento: contribuições para as práticas pedagógicas (pp. 347388). Campinas, SP: Komedi: Arte escrita.

Proença, M. (2002). Problemas de aprendizagem ou problemas de escolarização? Repensando o Cotidiano Escolar à luz da perspectiva Histórico-Crítica. Em M. K. Oliveira, D. T. R. Souza \& T. C. Rego (Org.), Psicologia, Educação e as temáticas da vida contemporânea (pp. 177-195). São Paulo: Moderna.

Sawaya, S. M. (2000). Alfabetização e fracasso escolar: problematizando alguns pressupostos da concepção construtivista. Educação e Pesquisa, 26(1), 67-81.

Scortegagna, P., \& Levandowski, D. C. (2004). Análise dos encaminhamentos de crianças com queixa escolar da rede municipal de ensino de Caxias do Sul. Interações, 9(18), 127-152.

Souza, M. P. R. de. (2008). Retornando à patologia para justificar a não aprendizagem escolar: a medicalização e o diagnóstico de transtornos de aprendizagem em tempos de neoliberalismo. ANPED. Recuperado: 01 fev. 2010. Disponível: http://www. 
anped.org.br/reunioes/31ra/4sessao_especial/se\%20-\%2012\%20

-\%20marilene\%20proena\%20rebello\%20de\%20souza\%20-\%20

participante.pdf
Zibetti, M. L. T., Souza, F. L. F de, \& Queiroz, K. J. M. (2010). Quando a escola recorre à psicologia: mecanismos de produção, encaminhamento e atendimento à queixa na alfabetização. Estudos e Pesquisas em Psicologia, 10(02), 490-506.

Recebido em: 06/09/2011

Aprovado em: 02/04/2012

\section{Sobre as autoras}

Marli Lúcia Tonatto Zibetti (marlizibetti@yahoo.com.br)

Departamento de Psicologia - Universidade Federal de Rondônia, Doutorado em Psicologia Escolar e do Desenvolvimento Humano. Endereço para Correspondência: Rua Uruguai, 2955 - Apart. 101, Bairro Embratel, CEP. 76820.884 - Porto Velho - RO.

Flávia Pansini (flaviapansini3@yahoo.com.br)

Departamento de Educação - Universidade Federal de Rondônia, Mestrado em Ciências da Linguagem. Endereço para Correspondência: Travessa Topázio, 3741, Bairro Centenário, CEP: 76940-000 - Rolim de Moura - RO.

Flora Lima Farias de Souza (florafarias@yahoo.com.br)

Mestrado em Psicologia - Universidade Federal de Rondônia, Graduação em Pedagogia. Endereço para Correspondência: Rua Luis de Camões 6349, Bairro Aponiã, CEP: 768224-064 - Porto Velho - RO.

Apoio Financeiro do CNPq. 